\title{
Influence of the laser-based surface modification on the bond strength for friction press joining of aluminum and polyethylene
}

\author{
Analysis of the temperature profile and the surface texture as a way to characterize the \\ friction press joining process
}

\author{
Stefan P. Meyer ${ }^{1}\left[\right.$. Christoph Wunderling ${ }^{1} \cdot$ Michael F. Zaeh $^{1}$
}

Received: 14 October 2019 / Accepted: 23 October 2019 / Published online: 3 November 2019

(c) The Author(s) 2019

\begin{abstract}
Friction press joining is an innovative joining process for the production of plastic-metal joints without additives, in an overlap configuration. In order to achieve a high bond strength, the metallic joining partner is pretreated with laser radiation. Subsequently, heat is induced by friction and pressure during the joining process, causing the thermoplastic material to melt and adhere to the metallic joining partner. In this work, the temperature distribution during the process in the composite is analyzed and characterized. It was found that the occurring temperatures and temperature differences are not only dependent on the rotational speed, but also on the feed rate. It is also shown that the friction surface temperature can be used as an indirect control variable for a model-based, closed-loop control. Based on these findings, various surface modifications for the metallic joining partner were investigated and analyzed with regard to the maximum strength of the joint. It was observed that the highest tensile shear strength can be achieved with a quasi-chaotic nano structure. In addition, the joining compound was characterized by a thin section, facilitating the identification of specific zones in the joint. These investigations show the high potential for friction press joining of plastics and metals, and form the basis for a model-based control of the joining zone temperature.
\end{abstract}

Keywords Friction press joining $\cdot$ Polymer metal joining $\cdot$ Aluminum $\cdot$ Thermoplastics $\cdot$ Hybrid bonds $\cdot$ Dissimilar material joining

\section{Introduction}

With the ratification of the ICAO Resolution A39-3, a global market-based climate-protection instrument in form of the offsetting system CORSIA (Carbon Offsetting and Reduction Scheme for International Aviation) will be globally launched in 2020 [1]. This makes international civil aviation the first industry in the world to have a global climateprotection instrument.

In order to achieve these ambitious goals, the $\mathrm{CO}_{2}$ emissions of aircraft must be reduced. In addition to the further development of more economical engines, lightweight design is a decisive factor in reducing kerosene consumption.

Stefan P. Meyer

stefan.meyer@iwb.mw.tum.de

1 Boltzmannstr.15, 85748 Garching, Germany
The use of lightweight materials, such as (fiber-reinforced) plastics, is an essential driving force towards this goal. Modern aircraft (Boeing 787 and Airbus 350-XWB) already consist of up to $50 \%$ carbon fiber-reinforced plastics in the body and wing structures [2]. However, these plastics are rarely used in an isolated form. They are mostly combined with metals. Especially with regards to the joining technology, this combination requires new approaches to join these different materials. A recently-developed approach to join plastics and metals is friction press joining (FPJ) [3].

FPJ is a joining technology based on friction stir welding (FSW), whereby the tool only has a shoulder, called the friction surface. The FPJ process itself is characterized by five phases:

Pretreatment

Here, the joining surface of the metallic joining partner is pretreated 
to improve the adhesion of the hybrid bond by changing the surface topology.

Touch-down phase In this phase, the tool rotates (rotational speed $n$ ) around the longitudinal axis. By applying an axial force $F_{a}$, the tool is pressed onto the joining surface in the negative $\mathrm{z}$-direction, causing the torque $M_{a}$. The touchdown phase ends when the tool has reached a certain z-position, or a given axial force is applied.

Dwelling phase

Welding phase

Retreat phase Due to the friction between the tool and the metallic joining partner, the process zone heats up. In addition, the material is deformed, which releases dissipation heat. These two phenomena result in the softening of the joining partners.

In this phase, a connection is formed between the two joining partners. The tool is guided along the welding trajectory at the selected feed rate $v$, forming a weld seam. As a result of the tool rotation, a heat flow from the metallic joining partner into the joining zone occurs. There, the plastic is melted and adheres to the pretreated joining surface.

The welding process ends with the tool being withdrawn from the process zone in the positive $\mathrm{z}$-direction.

The first phase (surface pretreatment of the metallic joining partner) is an upstream process. The actual joining process is comparable to FSW, and is divided into the four phases (see Fig. 1).

In the process, two distinctive temperatures occur: the friction zone temperature $T_{F}$ between the surface of the metallic workpiece and the tool (friction surface), and the joining zone temperature $T_{J}$ between the plastic component and the metal.

\section{State of the art}

\subsection{Friction press joining}

Friction press joining was first described by Wirth et al. [4] using the example of joining aluminum with polyamide. The focus of the study was to identify the influence of the surface topology of the metallic joining partner on the bond strength. Macroscopic structures (Surfi-Sculpt ${ }^{\circledR}$ ) were compared with microscopic structures. Both modifications produced undercuts, which allowed the molten plastic to penetrate the metal and anchor itself mechanically. The adhesion was therefore explained by the mechanical anchoring.

Wirth et al. [5] described a heat conduction process with constant contact pressure. It was assumed that these results could be transferred to friction press joining, but the authors did not give the proof. In their investigations it was demonstrated that the pressure on the joint and the temperature between the aluminum and the tool have a considerable influence on the bond strength.

Liu et al. [6] investigated friction lap welding (FLW), which differs from FPJ only by the fact that no surface pretreatment is applied. A linear relationship between the thickness of the molten layer of the plastic component and the input parameters rotational speed in square and feed rate was found.

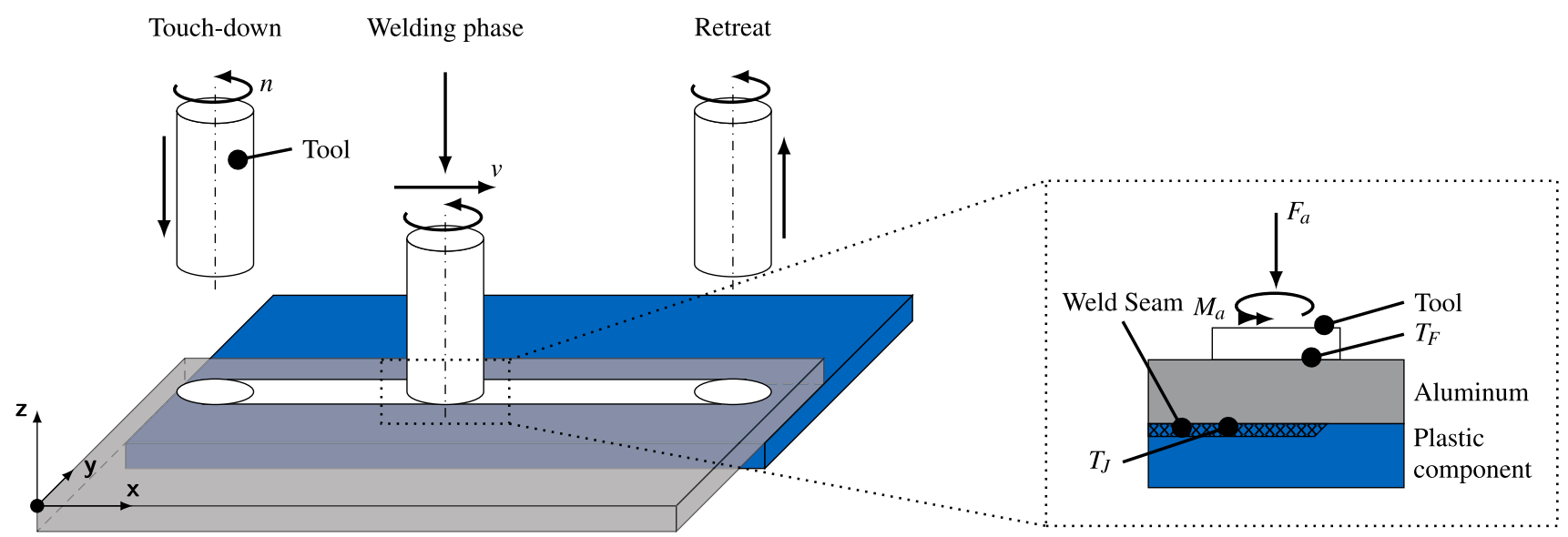

Fig. 1 Schematic description of the process of friction press joining with a polymer (blue) and a metallic joining partner (gray) with indicated movement (arrow) 
Nagatsuka et al. [7] also used friction lap welding to join fiber-reinforced polyamide 6 and aluminum A5052. For the first time, the influence of the surface of the metallic joining partner was investigated. By grinding the surface, a significant increase in the bond strength could be achieved.

Buffa et al. [8] used a modified FSW process to join aluminum with polypropylene. Holes were drilled in the metal to be joined, allowing the molten plastic to flow through and thus form a form closure with the aluminum. The contact pressure was identified as a significant influencing factor.

Meyer et al. [3] showed, by using the example of aluminum EN AW-6082-T6 and high density polyethylene (PE$\mathrm{HD}$ ), that the joining zone temperature $T_{J}$ strongly determines the bond strength. It was shown that both too much (plastic degraded) and too little energy input (plastic did not melt sufficiently) have a negative effect on the bond strength.

\subsection{Pretreatment for hybrid bonds}

Heckert et al. [9] showed in their studies on laser-based thermal joining that surface pretreatment has a strong influence on the bond strength. For the combination of aluminum (EN AW-6082-T6) and polyamide with $30 \%$ glass fiber-reinforcement (PA6-GF30), continuous wave (CW) processes are advantages over pulsed (PW) laser processes with regard to the bond strength. Furthermore, the authors introduced the distinction between macro-, micro-, and nanoscopic surface structures.

Based on these results, Wunderling et al. [10] investigated the effects of the $\mathrm{CW}$-process on the thermal distortion. They presented a new structuring strategy based on beam oscillation that promises high surface rates and low thermal distortions at the same time.

A frequently encountered material combination of plastic-metal hybrid joints is the combination of aluminum and polyamide (PA). Therefore, Mitschang et al. [11] investigated this combination for inductive joining. The surface pretreatment was identified as a significant factor influencing the bond strength, which allowed the bond strength to be doubled.

However, surface pretreatment is not limited to plasticmetal composites. Plastic-plastic composites of mutually incompatible plastics are also the subject of research. Thus Wolf et al. [12] showed for the incompatible material combination PA66 and PE-HD that a bond is possible if the surface of the polyamide is pretreated accordingly. For this purpose, a surface structure is introduced into the plastic component with the higher melting point (PA66) by vibration. The PE-HD is then applied by vibration welding. A form closure was identified as the bonding mechanism. According to the authors, this allows incompatible materials to be joined.

\section{Objective and approach}

The goal of this study was to characterize the parameter range for joining aluminum with polyethylene as a function of the rotational speed and the feed rate, and to investigate derived variables (e.g. temperature) regarding their suitability as input parameters for a closed-loop controller. As a second step, the influence of different surface pretreatment strategies, using laser radiation, was evaluated. For this purpose, the nano- and microstructuring strategy of Heckert et al. [9] and the oscillation strategy of Wunderling et al. [10] were studied in view of friction press joining. Finally, a characterization of the joining zone in the bonded condition was analyzed and described.

\section{Material and experimental set-up}

\subsection{Specimen material}

In this study the friction press joining of aluminum and polyethylene was investigated.

The aluminum wrought alloy used was an EN AW6082 -T6 $\left(250 \times 100 \times 5 \mathrm{~mm}^{3}\right)$, supplied by Gemmel \& $\mathrm{Co}$. $\mathrm{GmbH}$ [13]. This $\mathrm{Al}-\mathrm{Mg}-\mathrm{Si}$ alloy has a high corrosion resistance as well as a good formability and a high weldability.

A high density polyethylene (PE-HD) was used as the plastic joining partner $\left(250 \times 100 \times 5 \mathrm{~mm}^{3}\right)$, supplied by S-Polytec GmbH (see Table 1). In addition to a low density (compared to other polymers), a high crystallinity, and a good chemical resistance, this plastic group has a low water absorption capability. For these reasons, these plastics are used in a wide range of applications, from powder materials $[14,15]$ to hip implants [16].

\subsection{Welding system and clamping}

The experiments were conducted on a Heller MCH250 CNC milling machine. The tool spindle was arranged horizontally in the machining area and could be moved in $\mathrm{x}$ - and $\mathrm{y}$-direction. The tilt angle was obtained by rotating the clamping

Table 1 Selected properties of the polyethylene used in the experiments [17]

\begin{tabular}{ll}
\hline Properties & \\
\hline Melting range & $126-130^{\circ} \mathrm{C}$ \\
Mean coefficient of linear thermal expansion & $1.8 \times 10^{-4} \mathrm{~K}^{-1}$ \\
Thermal conductivity & $0.38 \mathrm{Wm}^{-1} \mathrm{~K}^{-1}$ \\
Yield stress & $23 \mathrm{MPa}$ \\
\hline
\end{tabular}


base. Figure 2 shows the clamping system. The two joining partners were arranged with an overlap of $35 \mathrm{~mm}$. The tool used was a hardened C45 steel with a shoulder diameter of $25 \mathrm{~mm}$ and a flat friction surface (see Fig. 3).

\subsection{Laser systems for surface pretreatment}

Two different laser systems, as also utilized in $[9,10]$ were used to pretreat the aluminum side of the joining surface. A pulsed fiber laser system PowerlineF20 from Rofin-Sinar $\mathrm{GmbH}$ was applied for the nanoscopic structures. The maximum power was $20 \mathrm{~W}$ at a wavelength of $\lambda=1064 \mathrm{~nm}$. The pulse frequency of the laser system could be adjusted between $20 \mathrm{kHz}$ and $100 \mathrm{kHz}$. The structures generated by this laser system are characterized by a fine oxide layer.

For the microscopic structures, a single-mode fiber laser YLR-3000-SM supplied by IPG Photonics Corporation was used. This laser emitted radiation with a wavelength of $\lambda=1070 \mathrm{~nm}$ at a maximum power of $P_{\max }=3 \mathrm{~kW}$. The beam was guided by a galvanometer scanner optic system provided by Arges $\mathrm{GmbH}$ and had a spot diameter of approximately $60 \mu \mathrm{m}$ [18]. The working distance was $406 \mathrm{~mm}$. The structures were created by remote ablation cutting (RAC) and were characterized by kerfs. The generated surface topographies are classified as microstructures.

\subsection{Analytical set-up}

Various measuring instruments and methods were used to characterize the produced composites and the process.

For the analysis of the temperature between the tool and the aluminum surface $\left(T_{F}\right)$, a thermocouple (type $\mathrm{K}$ ) was inserted into the FPJ tool according to [19]. The hole was located $6.25 \mathrm{~mm}$ from the center of the tool, and thus between the center and the circumference (see Fig. 3b). The thermocouple was connected to a measuring unit on the

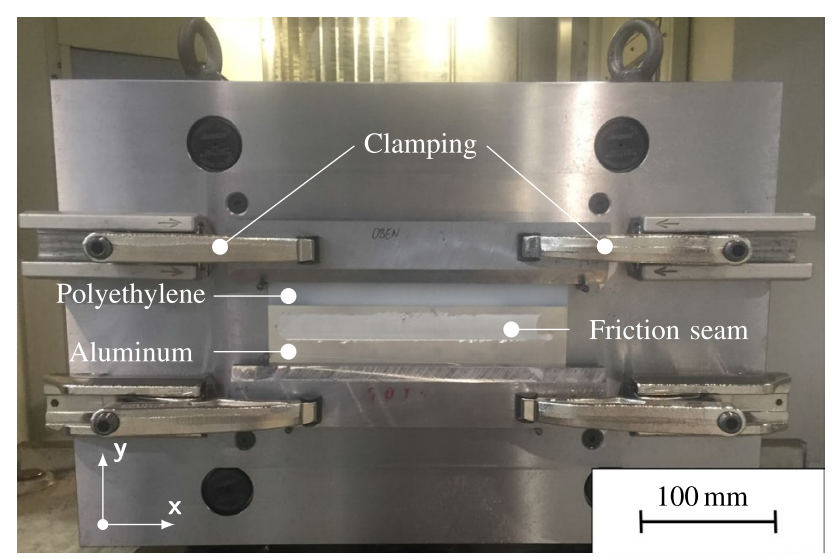

Fig. 2 Clamping system for joining aluminum and polyethylene by friction press joining

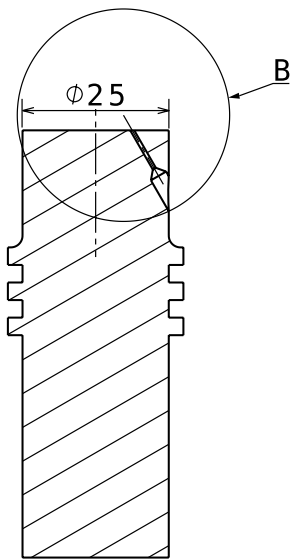

(a) Cross section

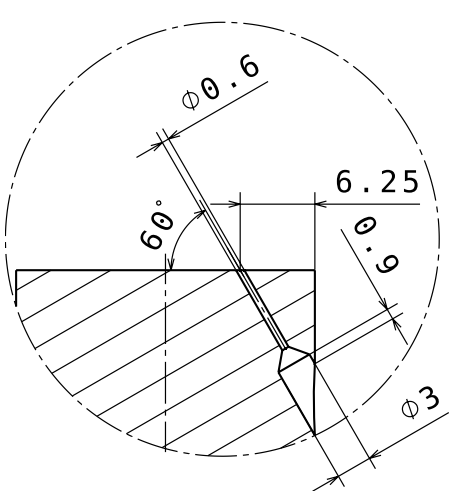

(b) Detail B
Fig. 3 Cross sectional view of the FPJ tool (a) and detailed view (b) of the thermocouple hole for measuring the temperature $T_{F}$

spindle, which transmitted the temperatures via WiFi for recording and further processing.

To measure the temperature $T_{J}$ in the composite, type $\mathrm{K}$ thermocouples were welded into the bond. For this purpose, grooves $(0.5 \mathrm{~mm}$ deep) were machined into the metal joining partner, which were filled with a heat-conducting paste and then equipped with thermocouples and overlapped with the plastics. These grooves ensured that the temperature $T_{J}$ was measured directly below the center of the tool. Correspondingly, the temperature in the aluminum $T_{A l}$ was determined at a depth of $1.5 \mathrm{~mm}$ and $5 \mathrm{~mm}$ away from the friction surface (see Fig. 4). The measuring point $T_{8}$ was shifted in comparison to the other thermocouples, as it served for the validation of a simulation model which is not subject of this paper.

The contact pressure $F_{a}$ and the spindle torque $M_{a}$ were measured by a sensor unit, which was integrated between the Weldon adapter for the FPJ tool and the SK50 adapter for the spindle. The signal transmission as well as the power supply

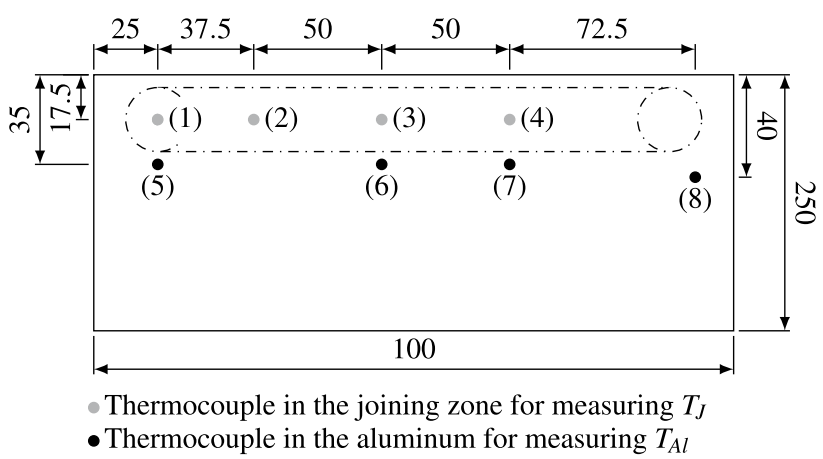

Fig. 4 Position of the thermocouples in the aluminum and joining surface for determination of the joining zone temperature and the temperature in the aluminum, with indicated friction track 
work wirelessly via induction. The measurement data were sent from the rotating sensor unit (rotor) to a receiver (stator) mounted in the working chamber. The sampling frequency was $9600 \mathrm{~Hz}$.

To determine the tensile strength, a tensile-testing machine from Zwick-Roell (Z150) was used. For this purpose, five tensile shear specimens, each with a width of $25 \mathrm{~mm}$, were cut out of the joint. To ensure constant welding conditions, the first sample was cut out $70 \mathrm{~mm}$ after the weld seam start. The tensile tests were conducted with a preload of $20 \mathrm{~N}$ and a traversing speed of $50 \mathrm{~mm} \mathrm{~min}^{-1}$. The clamping length was $115 \mathrm{~mm}$.

\section{Friction press joining of aluminum and polyethylene}

\subsection{Friction press joining-process window}

To determine the process window, the results from [3] were used as a basis. The rotational speed $n$ was varied fullyfractionally from 400 to $1000 \mathrm{~mm}^{-1}$ in steps of $200 \mathrm{~mm}^{-1}$ and the feed rate $v$ from 150 to $750 \mathrm{~mm} \mathrm{~min}^{-1}$ in steps of $150 \mathrm{~mm} \mathrm{~min}^{-1}$. The angle of attack was $\alpha=1^{\circ}$ with a plunging depth $E_{t}=0.15 \mathrm{~mm}$. The friction length was set to $200 \mathrm{~mm}$.

Since the temperatures in the joining zone $\left(T_{J}\right)$ and in the aluminum $\left(T_{A l}\right)$ could only be measured at certain points, but the friction surface temperature $\left(T_{F}\right)$ continuously, the following diagram was obtained (see Fig. 5). The temperature $T_{F, \text { max }}$ was evaluated from the maximum occurring temperature at the individual measuring points $( \pm 12.5 \mathrm{~mm})$. This measuring range corresponds to half the tool diameter.
That ensures that the edge areas of the tool, which have the highest relative speed and thus the greatest influence on the maximum joining zone temperature, were included in the temperature evaluation (see Fig. 5).

Figure 5 indicates that a stationary state of the temperature was reached at an x-position of approximately $75 \mathrm{~mm}$ after the start of the welding and for the axial force at an $\mathrm{x}$-position of approximately $100 \mathrm{~mm}$ after the start of the welding. For this reason, the temperatures at position 4 (at $x=137.5 \mathrm{~mm}$ ) were considered for the analysis thereafter.

The temperature in the joining zone $\left(T_{J, 4, \max }\right)$ at position 4 indicates that the temperature increases with higher rotational speed $n$, and decreases with increasing feed rate $v$ (see Fig. 6). This could also be proven for the other parameter sets. For a better readability, only the feed rates $v_{1}=450 \mathrm{~mm} \mathrm{~min}^{-1}$ and $v_{2}=600 \mathrm{~mm} \mathrm{~min}^{-1}$ are described

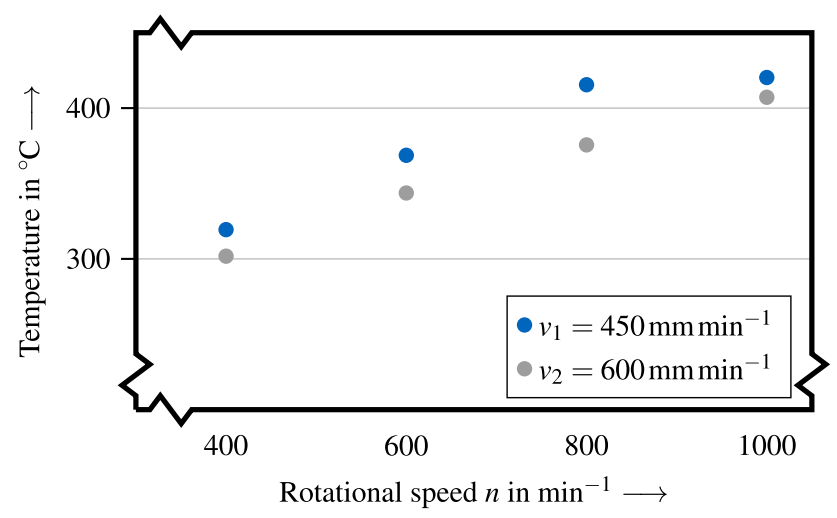

Fig. 6 Plot of the maximum joining zone temperature $\left(T_{J, 4, \max }\right)$ at two different feed rates $\left(v_{1}=450 \mathrm{~mm} \mathrm{~min}^{-1}\right.$ and $\left.v_{2}=600 \mathrm{~mm} \mathrm{~min}^{-1}\right)$ over the rotational speed $n$

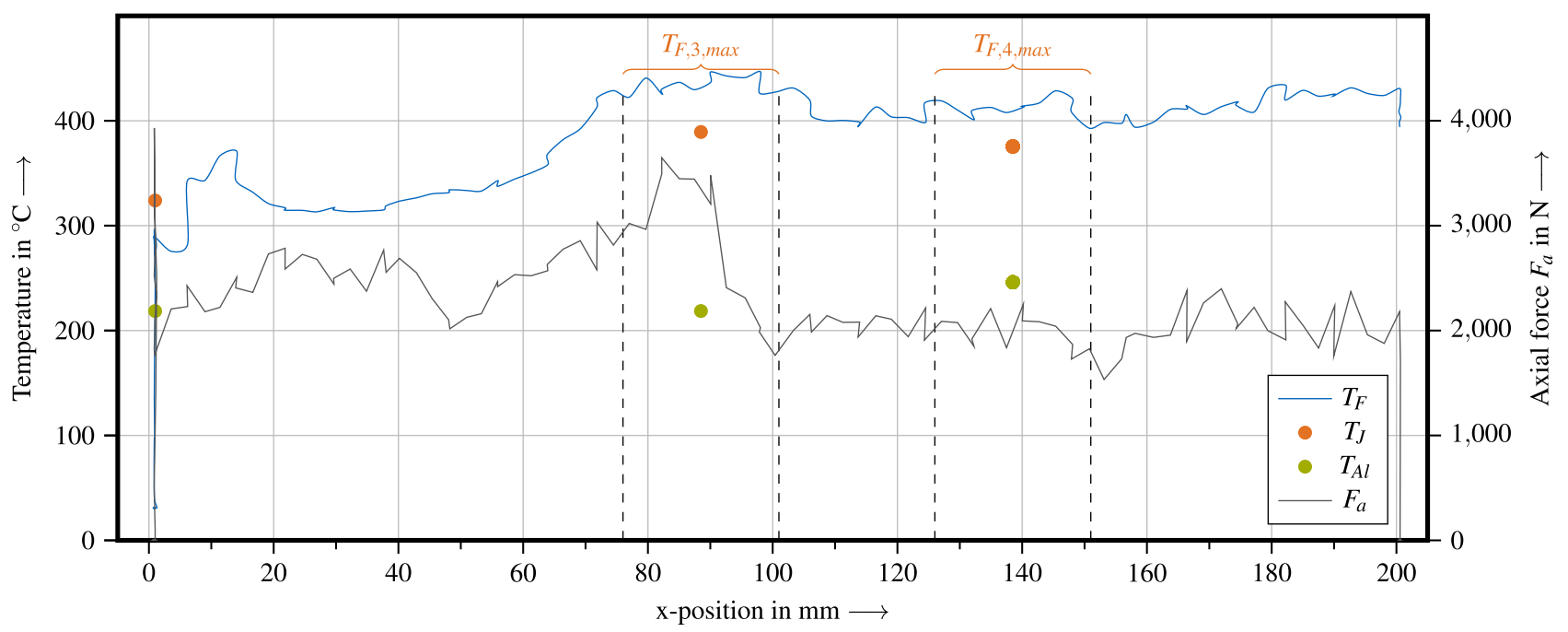

Fig. 5 Temperatures during friction press joining with $v=600 \mathrm{~mm} \mathrm{~min}^{-1}$ and $n=800 \mathrm{~min}^{-1}$ at the positions $1,3,4\left(T_{J}\right)$ and $5,6,7\left(T_{A l}\right)$ as well as the tool temperature $T_{F}$, and the axial force $F_{a}$ 
in detail in the following. Also the friction surface temperature $\left(T_{F, 4, \max }\right)$ follows the same regularity, only at higher temperatures.

The temperature difference

$$
\Delta T=T_{F}-T_{J}
$$

between the friction surface temperature $T_{F}$ and the joining zone temperature $T_{J}$ depends on the rotational speed $n$ and on the feed rate $v$ (see Fig. 7). The temperature difference $\Delta T$ increased with increasing rotational speed as well as with increasing feed rate.

By way of a sufficient approximation, the process can be considered as a stationary heat conduction problem. Thus, the temperature difference $\Delta T$ increases with increasing friction surface temperature (increasing rotational speed $n$ ) and a constant temperature of the clamping system (high thermal capacity in relation to the workpiece). The influence of the feed rate was explained with the instationary heat conduction with an ideally insulated support on one side. Thus, the contact time period for the tool and the measuring point (energy input) decreases with higher feed rates (the tool is guided faster over the measuring point). This reduces the temperature uniformity and maximizes the temperature difference between $T_{J}$ and $T_{F}$. For further studies, the instationary heat conduction should be used as the basis for a model to cover all aspects.

In summary, both the friction surface temperature $T_{F}$ and the joining zone temperature $T_{J}$ depend on the rotational speed $n$ and the feed rate $v$ (see Table 2). The higher the rotational speed and the lower the feed rate, the higher are the resulting temperatures. Furthermore, it was shown that the temperature difference $\Delta T$ increased with increasing rotational speed and increasing feed rate. However, no linear

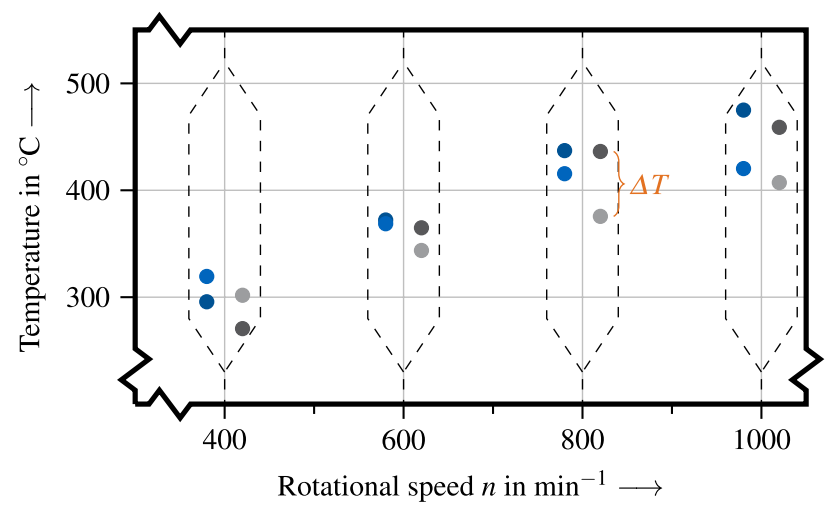

$\bullet T_{F, 4, v=450} \bullet T_{J, 4, v=450} \bullet T_{F, 4, v=600} \bullet T_{J, 4, v=600}$

Fig. 7 Plot of the maximum joining zone temperature $\left(T_{J, 4, \max }\right)$ and the corresponding maximum friction surface temperature $\left(T_{F, 4, \max }\right)$ for two different feed rates $\left(v_{1}=450 \mathrm{~mm} \mathrm{~min}^{-1}\right.$ and $v_{2}=600 \mathrm{~mm} \mathrm{~min}^{-1}$ ) over the rotational speed $n$
Table 2 Summary of the influencing factors "rotational speed" and "feed rate" on the different temperatures

\begin{tabular}{lll}
\hline Temp. & Rotational speed $n \uparrow$ & Feed rate $v \uparrow$ \\
\hline$T_{F}$ & $\uparrow$ & $\downarrow$ \\
$T_{J}$ & $\uparrow$ & $\downarrow$ \\
$\Delta T=T_{F}-T_{J}$ & $\uparrow$ & $\uparrow$ \\
\hline
\end{tabular}

correlation between the parameters $n$ and $v$ and the process responses $T_{F}$ and $T_{J}$ was identified so far.

As already indicated in Fig. 5, the settling time until a steady state was reached is long. For this reason, a temperature-controlled and a force-controlled FPJ process will be investigated in future work.

\subsection{Friction press joining-surface texturing}

Based on the previous investigations to determine the parameter range and the associated temperatures, the influence of the applied pretreatment method was investigated. For this purpose, several laser-based textures were preselected and prepared in a first step.

In total, three different surface-structuring strategies were compared. The first strategy was based on Heckert et al. [9] and uses a pulsed laser system to generate nanoscopic structures. Table 3 shows the laser parameters with a total of four different structures (see Fig. 9). Structure $n l$ was a quasichaotic structure in which the individual exposure points overlap $\left(p_{s}\right)$ (see Fig. 8a). Structures $n 2$ to $n 4$ were nanoscopic grid structures in which the exposure points overlap in the individual lines $\left(d_{l}\right)$, but the different lines show a certain distance (see Fig. 8 b). Three lines, under $0^{\circ}, 60^{\circ}$, and $120^{\circ}$, were created per exposure (Fig. 9).

In particular, the quasi-chaotic nanostructure $(n l)$ shows a continuous porous oxide structure with fine structures similar to ramifications. The nanoscopic grid structures $(n 2-n 4)$ showed different depressions. Small holes were created at the intersections, while next to the exposed lines, the metallic surface was not modified.

Table 3 Laser parameter sets used for the generation of nanoscopic structures with a Rofin Powerline F20

\begin{tabular}{lllll}
\hline No. & Power in W & Exposures & $\begin{array}{l}\text { Line spacing } \\
d_{l} \text { in } \mu \mathrm{m}\end{array}$ & $\begin{array}{l}\text { Pulse spac- } \\
\text { ing } p_{s} \text { in } \\
\mu \mathrm{m}\end{array}$ \\
\hline$n 1$ & 20 & 2 & 25 & 25 \\
$n 2$ & 20 & 3 & 200 & 25 \\
$n 3$ & 20 & 1 & 200 & 15 \\
$n 4$ & 15 & 1 & 200 & 25 \\
\hline
\end{tabular}

All structures were generated with a pulse frequency of $20 \mathrm{kHz}$ 


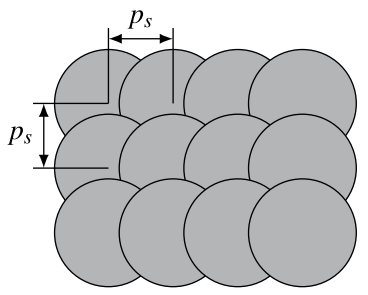

(a)

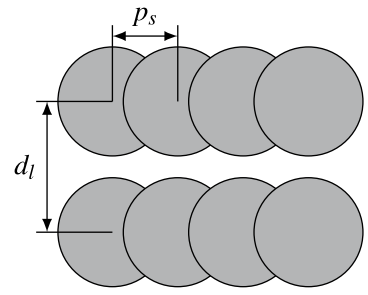

(b)
Fig. 8 Comparison of the pulse pattern for a chaotic nanostructure (a) and a line-based nanostructure (b)

The second as well as the third structuring strategy were each based on a microscopic structure generated by a continuous wave laser system. This high power laser used a remote ablation cutting process in which kerfs are cut into the surface. The idea is that the molten plastic hooks into these kerfs and thus creates a form-fit with the aluminum.

The second structuring strategy was based on a microscopic grid structure (see Fig. 10a). Several overlaps create kerfs in the surface (see Table 4). These kerfs were arranged at $0^{\circ}$, $60^{\circ}$, and $120^{\circ}$ to create a direction-independent structure (see Fig. 11).

The parameters in Table 5 were used for the oscillation structures. The indicated feed rate $v_{L}$ refers to the linear movement. This linear motion is superimposed with a circular motion of amplitude $A_{O}$ and frequency $f_{O}$. This produced the typical circular pattern (see Fig. 10b). The resulting trajectory velocity $v_{\text {res }}$ was calculated according to [10] as a superimposed movement with:

$v_{\text {res }}=\sqrt{v_{L}+\left(2 \pi f_{O} A_{O}\right)^{2}+4 \pi A_{O} v_{L} \times \cos \left(2 \pi f_{O} t\right)}$.

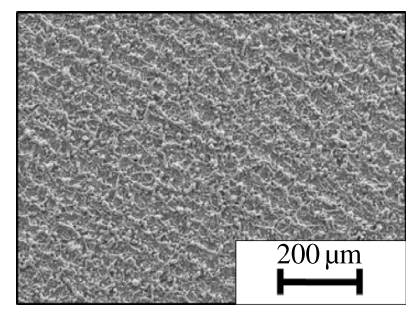

(a) $n 1$

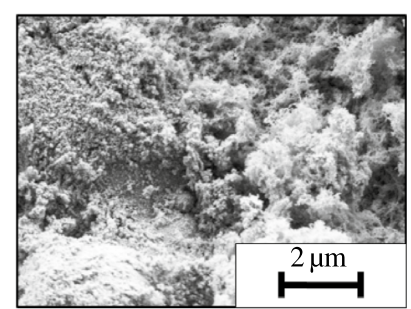

(e) $n 1$

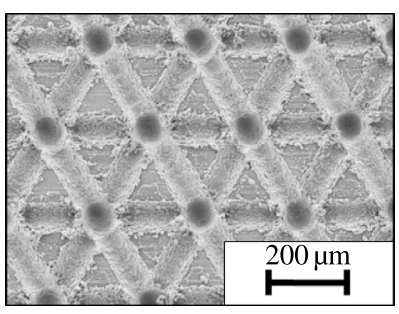

(b) $n 2$

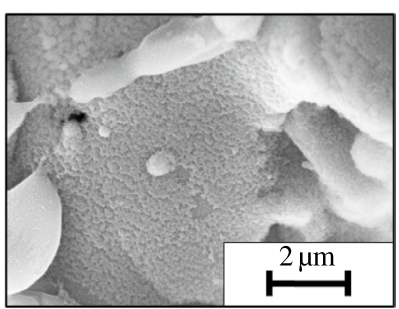

(f) $n 2$

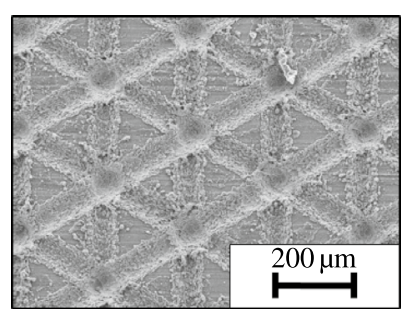

(c) $n 3$

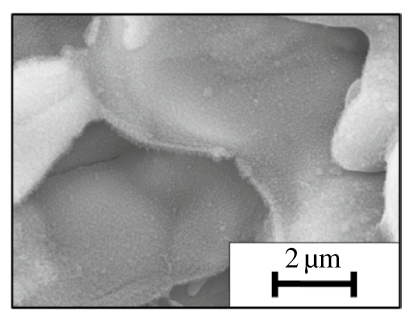

(g) $n 3$

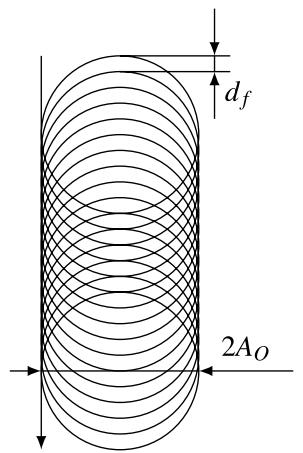

(b)
Fig. 10 A depiction of the grid structure $(\mathrm{G})(\mathbf{a})$ and the oscillation structure $(\mathrm{O})(\mathbf{b})$

Due to the fact that the maximum amplitude, and thus the radius, of the laser beam is $10 \mathrm{~mm}$, two or four paths were placed next to each other for the overlap joints in order to structure a width of $40 \mathrm{~mm}$ (see Fig. 11).

In the images of the surface of the microscopic structures in the range of $200 \mu \mathrm{m}$, a distinctly rough surface can be seen, with peaks and notches into which the plastic can mechanically hook (see Fig. 11). In the case of the oscillation structure, untreated aluminum surfaces are recognizable as well. In the range of $2 \mu \mathrm{m}$, fine structures with crater-like surfaces could be detected. In contrast to the nanoscopic structure, these surfaces appear smoother and less porous in the range of $2 \mu \mathrm{m}$.

Fig. 9 SEM images of the nanoscopic samples with two different magnifications; $n 1$ shows the quasi-random laser structuring; $n 2-n 4$ show the nanoscopic grid structure 
Table 4 Laser parameters for the generation of macroscopic grid structures in a CW-process

\begin{tabular}{llcll}
\hline No. & Power in $\mathrm{W}$ & $\begin{array}{l}\text { Feed rate } v_{L} \text { in } \\
\mathrm{mm} \mathrm{s}^{-1}\end{array}$ & $\begin{array}{l}\text { Line spacing } \\
d_{l} \text { in } \mathrm{mm}\end{array}$ & Exposures \\
\hline$G 1$ & 1000 & 12,000 & 0.4 & 5 \\
$G 2$ & 1500 & 8000 & 0.3 & 1 \\
$G 3$ & 1500 & 10000 & 0.4 & 3 \\
$G 4$ & 2000 & 8000 & 0.3 & 5 \\
\hline
\end{tabular}

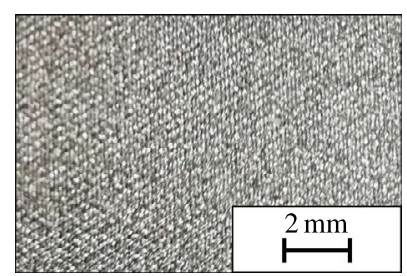

(a) G4

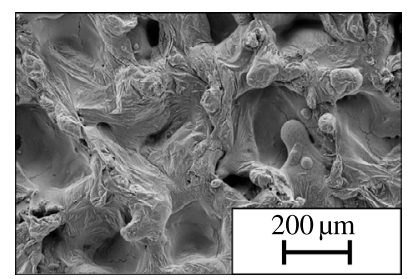

(c) $G 4$

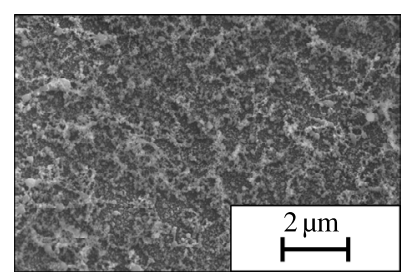

(e) $G 4$

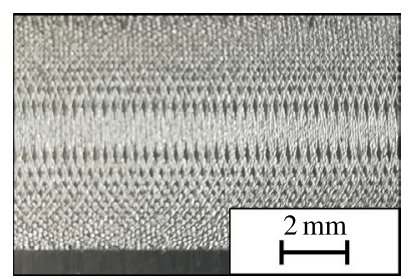

(b) 04

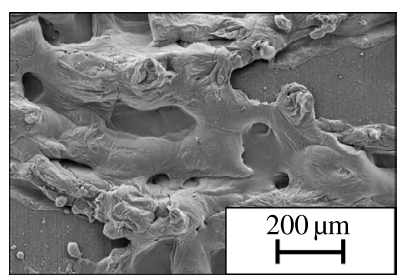

(d) 04

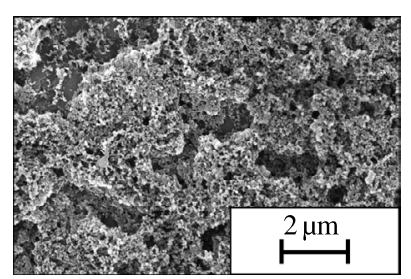

(f) $\mathrm{O} 4$
Fig. 11 Images of the grid structure $G 4$ and the oscillation structure $O 4$ at different resolutions

Table 5 Laser parameters for generating oscillation structures using a CW-process

\begin{tabular}{llllll}
\hline No. & Power in W & $\begin{array}{l}\text { Feed rate } v_{L} \\
\text { in } \mathrm{mm} \mathrm{s}^{-1}\end{array}$ & $\begin{array}{l}\text { Amplitude } \\
A_{O} \text { in mm }\end{array}$ & Freq. in Hz & Exp. \\
\hline O1 & 1500 & 75 & 10 & 90 & 1 \\
O2 & 1500 & 75 & 5 & 90 & 1 \\
O3 & 2000 & 75 & 5 & 90 & 3 \\
O4 & 2000 & 75 & 10 & 90 & 3 \\
\hline
\end{tabular}

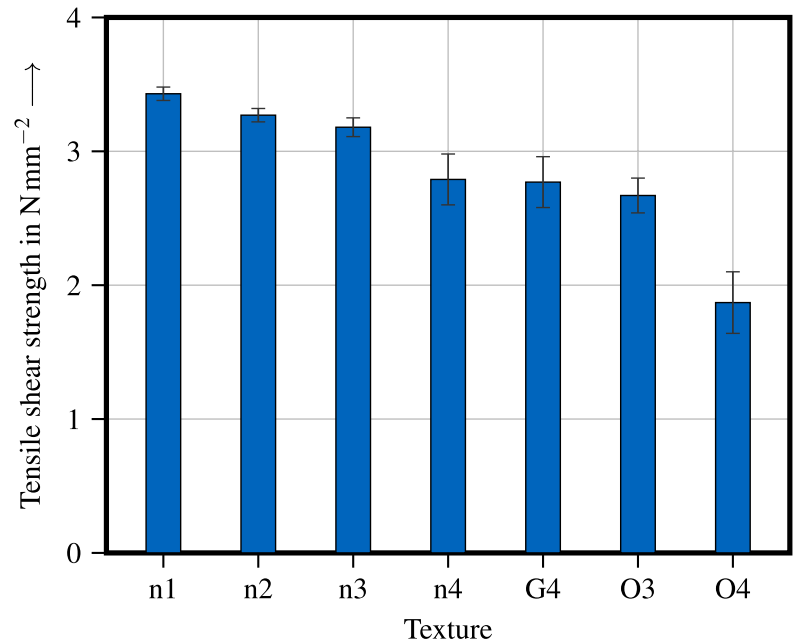

Fig. 12 Results of the tensile shear tests of the different structures with an overlap of $35 \mathrm{~mm}$

\subsection{Friction press joining-influence of the surface texture}

In Sect. 5.1 and based on the findings of [3] the parameters with a rotational speed of $n=800 \mathrm{~min}^{-1}$ and a feed rate of $v=450 \mathrm{~mm} \mathrm{~min}^{-1}$ indicated that the generated heat input is suitable for the given material combination to produce a compound with a high bond strength. Therefore, the generated structures from Sect. 5.2 were joined with this parameter set and evaluated with regard to the tensile shear strength.

The overlap was set to $35 \mathrm{~mm}$, in order to be able to compare the results with those in [3]. From the joints $(250 \mathrm{~mm})$, five tensile specimens with a width of $25 \mathrm{~mm}$ were prepared and tested destructively on a tensile-testing machine (Zwick Z150) as mentioned in Sect. 4.4.

Based on the results, the nanoscopic structures $(n 1-n 3)$ show an increased tensile shear strength compared to the other two strategies (see Fig. 12). With the grid structures G1-G3 no quantifiable connection could be produced. Compounds with these structures fractured during the sample preparation. The oscillation structures $\mathrm{O} 1$ and $\mathrm{O} 2$ similarly showed low tensile shear strengths. Durable compounds could only be produced with the multiple exposed oscillation structures $O 3$ and $O 4$.

The nanoscopic structures produced with the pulsed laser system possess of highly porous oxide layers, which have been verified for titanium alloys and examined more closely [20, 21]. These structures show high surface enlargements compared to the untreated surfaces. As a result, the free surface energy is increased, which also leads to an increase in the tensile shear strength of the bonds [22]. Due to the nonpolar character of the thermoplastic joining partner, which excludes the polarization theory, and the large surface of the 
metal, it is assumed that the increased van der Waals forces are the main bonding mechanism.

The microscopic structures are based on undercuts and kerfs in order to allow a form fit (mechanical anchoring) [23]. This bonding mechanism seems to be of secondary importance for the given material combination and joining process, since the nanoscopic structures offer both higher surface enlargements and higher tensile strengths.

In summary, it can be stated that nanoscopic structures with extensive oxide layers are advantageous for the given material combination for friction press joining.

\subsection{Friction press joining-joining zone characterization}

The structure of a direct joint produced by FPJ is similar to the one of an adhesive joint. However, there are some unique characteristics in the layered set-up that have not yet been classified. In order to qualify these characteristics, thin sections with a thickness of approximately $500 \mu \mathrm{m}$ were produced. This enables the detection of changes in the plastics by means of transmitted light via a microscope (see Fig. 13).

The formation of a direct joint can be separated into four layers. In the following, the single layers are described from the top (aluminum) to the bottom (polyethylene), as shown in Fig. 13:

Base material 1 The base material (aluminum) is not changed by the heat input. There are no modifications, mixing, or other interactions with the thermoplastic in this area. There are only cohesive forces.

Boundary layer In the boundary layer between the metal and the plastic, the plastic interlocks mechanically with the existing structures of the metal. In addition to mechanical adhesion, physical, chemical, or thermodynamic effects such as Van-der-Waalsforces, chemisorption, diffusion, or polarization occur in this area. In the case of an adhesive failure, the bonding fails in this layer.

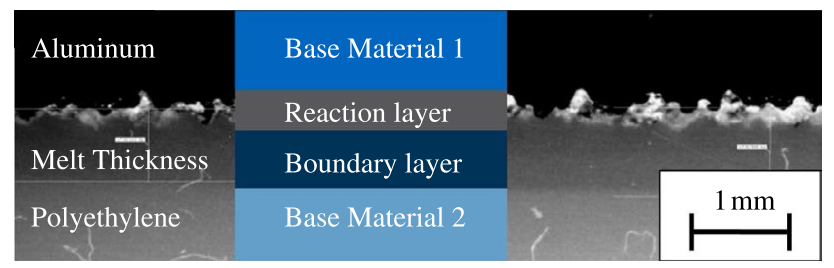

Fig. 13 Micrograph of an FPJ specimen (approx. $500 \mu \mathrm{m}$ thick) with indicated layers of a direct joint
Reaction layer In the reaction zone, the plastic melts during the joining process and deforms significantly. The thickness of this layer is a major indicator of the energy introduced into the composite. In this layer only cohesive forces are acting.

Base material 2 No structural changes can be observed in the second base material (plastic), since neither the melting temperature nor the glass transition temperature of the plastic was exceeded.

The boundary layer in particular was influenced by the surface pretreatment of the metallic joining partner. Depending on the structure used, different adhesion forces dominate. The more plastic is melted, i.e. the more energy is introduced over the time, the better it can fill and bond the structures. The structure should therefore be adapted to the thermoplastic joining partner in order to achieve the maximum bond strength.

The thickness of the reaction zone can be used as an indicator of the energy input, and thus serves as a quality parameter.

\section{Summary and conclusions}

The aim of this study was to characterize the parameter range for the friction press joining of aluminum and polyethylene. For this purpose, a fully-fractionally experiment was conducted and the process temperatures analyzed. A correlation between the process parameters "rotational speed" and "feed rate" with regard to the friction surface temperature and the joining zone temperature was shown (see Table 2). Furthermore, a quasi-chaotic nanoscopic structure generated with a pulsed laser system was be identified as the pretreatment method leading to the highest bond strength for the given material combination. Also, the joint was characterized by a thin section, where the boundary layer and reaction layer could be identified as key layers. In summary, the following conclusions can be derived:

C1 The temperatures $T_{F}, T_{J}$, and $\Delta T$ can be controlled via the process parameters $n$ and $v$.

C2 The joining zone temperature $T_{J}$ has to be controlled in order to keep the quality of the joint constant. For this purpose, the friction surface temperature $T_{F}$ can be used as an indirect controlling variable for a modelbased controller.

C3 The axial force $F_{a}$ is not stable over the weld length. This aspect has to be investigated further.

C4 A quasi chaotic nanostructuring of the metallic surface, with a porous oxide layer, produced with a pulsed laser 
process, results in high bond strengths for PE-HD to aluminum alloys.

C5 For the direct joints generated by FPJ, the boundary layer was identified as the critical layer that significantly determines the tensile strength.

Future research efforts will be based on the mathematical description of the joining zone temperature as well as on the development and investigation of the influence of a force control system on the process.

Acknowledgements This work was funded by the Deutsche Forschungsgemeinschaft (DFG, German Research Foundation)-418104776.

\section{Deutsche Forschungsgemeinschaft German Research Foundation}

Open Access This article is distributed under the terms of the Creative Commons Attribution 4.0 International License (http://creativeco mmons.org/licenses/by/4.0/), which permits unrestricted use, distribution, and reproduction in any medium, provided you give appropriate credit to the original author(s) and the source, provide a link to the Creative Commons license, and indicate if changes were made.

\section{References}

1. ICAO-International Civil Aviation Organization (2016). Resolution A39-3. https://www.icao.int/environmental-protection/ CORSIA/Documents/Resolution_A39_3.pdf

2. Marsh G (2010) Reinf Plast 54(6):20. https://doi.org/10.1016/ S0034-3617(10)70212-5

3. Meyer SP, Wunderling C, Zaeh MF (2019) Proceedings of the 22nd international ESAFORM conference on material forming: ESAFORM 2019 (AIP Publishing 2019), AIP conference proceedings, p. 050031. https://doi.org/10.1063/1.5112595

4. Wirth FX, Fuchs AN, Rinck P, Zaeh MF (2014) Adv Mater Res 536:966-967. https://doi.org/10.4028/www.scientific.net/ AMR.966-967.536

5. Wirth FX, Zaeh MF, Krutzlinger M, Silvanus J (2014) Proced CIRP 18:215. https://doi.org/10.1016/j.procir.2014.06.134

6. Liu FC, Liao J, Nakata K (2014) Mater Des 54:236. https://doi. org/10.1016/j.matdes.2013.08.056
7. Nagatsuka K, Yoshida S, Tsuchiya A, Nakata K (2015) Compos B Eng 73:82. https://doi.org/10.1016/j.compositesb.2014.12.029

8. Buffa G, Baffari D, Campanella D, Fratini L (2016) Proced Manuf 5:319. https://doi.org/10.1016/j.promfg.2016.08.028

9. Heckert A, Zaeh MF (2014) Proceedings of the 33rd international congress on applications of lasers and electro-optics. In: Laser Institute of America (Laser Institute of America (LIA pub), San Diego/CA, 2014), vol 56, pp 1171-1181. https://doi.org/10.1016/j. phpro.2014.08.032

10. Wunderling C, Scherm M, Meyer S, Zaeh MF (2019) Highpower laser materials processing: applications, diagnostics, and systems VIII. In: Kaierle S, Heinemann SW (SPIE, 02.02.2019 - 07.02.2019), pp 1 - 11. https://doi.org/10.1117/12.2511937

11. Mitschang P, Velthuis R, Emrich S, Kopnarski M (2009) J Thermoplast Compos Mater 22(6):767. https://doi.org/10.1177/08927 05709105969

12. Wolf M, Kleffel T, Leisen C, Drummer D (2017) Int J Poly Sci 2017:1. https://doi.org/10.1155/2017/6809469

13. Gemmel Metalle \& Co. GmbH. Technical data sheet: AlMgSi1 F30

14. Schäfer C, Bryant JS, Osswald TA, Meyer SP (2017) Annual technical conference (ANTEC) of the society of plastics engineers (SPE), vol 2017. Society of Plastics Engineers, Anaheim

15. Schäfer C, Meyer SP, Osswald TA (2018) Poly Eng Sci 44:1391. https://doi.org/10.1002/pen.24847

16. Kurth M, Eyerer P, Ascherl R, Dittel K, Holz U (1988) J Biomater Appl 3(1):33. https://doi.org/10.1177/088532828800300102

17. S-POLYTEC GmbH. Technical data sheet: PE-HD

18. Schwab D, Schäfer E, Wunderling C, Meyer S (2018) In: 10th CIRP conference on photonic technologies LANE 2018 (CIRP) (2018)

19. Bachmann A, Gamper J, Krutzlinger M, Zens A, Zaeh MF (2017) Int J Adv Manuf Technol 93(1-4):1157. https://doi.org/10.1007/ s00170-017-0594-5

20. Kurtovic A, Brandl E, Mertens T, Maier HJ (2013) Int J Adhes Adhes 45:112. https://doi.org/10.1016/j.ijadhadh.2013.05.004

21. Zimmermann S, Specht U, Spieß L, Romanus H, Krischok S, Himmerlich M, Ihde J (2012) Mater Sci Eng A 558:755. https:// doi.org/10.1016/j.msea.2012.08.101

22. Sharpe LH, Schonhorn H (1964) Contact angle, wettability, and adhesion. In: Fowkes FM (eds) Advances in chemistry, vol 43. American Chemical Society, Washington, D.C., pp. 189-201. https://doi.org/10.1021/ba-1964-0043.ch012

23. Mittal KL, Pizzi A (1999) Adhesion promotion techniques: technological applications. In: Materials engineering ser, vol 14. CRC, Boca Raton. https://ebookcentral.proquest.com/lib/gbv/ detail.action?docID $=5379079$

Publisher's Note Springer Nature remains neutral with regard to jurisdictional claims in published maps and institutional affiliations. 